\title{
Fenomenologías arquitectónicas extraordinarias: experiencias no-dualistas y la reducción de Husserl
}

Dr. Arq. Julio Bermúdez, College of Architecture + Planning, University of Utah Traducción: Arq. Estela Barbero, fadu/unl; Dr. Arq. Julio Bermúdez

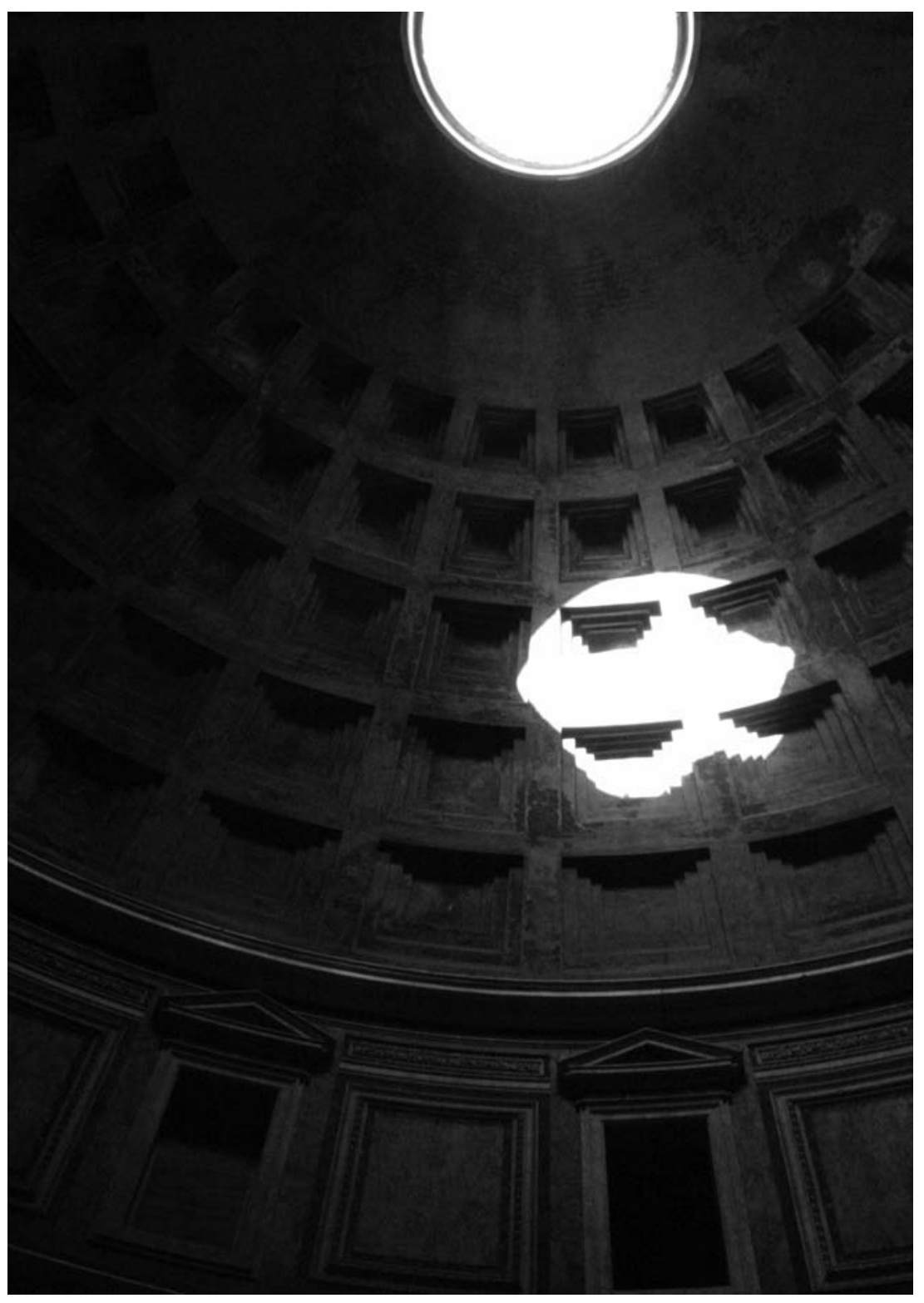

Figura 1. Panteón, Roma. Vista del óculo y cúpula en luz y sombra.
1. Introducción

Encuesta sobre estéticas excepcionales

A pesar de que los estudios fenomenológicos sobre lugares y obras de arquitectura consideran las estructuras y procesos de nuestra conciencia normal, se le ha prestado poca atención a las experiencias extraordinarias. Sin embargo, entender estas fenomenologías menos comunes sería muy útil en una variedad de frentes que abarca desde una mejor comprensión sobre qué es normal, a la consideración de conceptos ambientales y éticos asociados con el crecimiento descontrolado. La contribución de este trabajo es examinar la naturaleza de experiencias estéticas excepcionales del ambiente construido. A continuación hay cinco muestras de una encuesta representativa sobre las mencionadas fenomenologías. Arribar a esta selección no fue fácil, dado el gran número de fuentes confiables existentes ${ }^{1}$.

Los criterios de selección fueron evitar la repetición y cubrir una amplia gama de miradas experienciales. Cada muestra comienza con un párrafo que resume el punto principal de la cita literal que está a continuación. Incluí sólo el comentario suficiente para poner dicha cita en contexto.

Muestra 1: Las experiencias estéticas ocurren de pronto, crean anormalidades en la percepción espacio-tiempo, colapsan los límites que lo separan a uno de lo demás, son extraordinariamente vívidas y pueden lograr generar una epifanía experiencial. Luego de una larga introducción a su primera experiencia extraordinaria de lugar, el docente y artista Frederick Franks, dice «en ese momento algo pasó: se evaporaron todos mis miedos, y también las abejas, el sol, el pasto... y yo mismo. Porque en ese instante la luz solar y el cielo, los pastos, las abejas y yo nos fundimos, nos fusionamos, nos unificamos (a pesar de que seguíamos siendo sol, pasto, abejas y yo). Duró lo que un latido, una hora, un año... luego, abruptamente volví a ser yo nuevamente pero lleno de un indescriptible éxtasis.... ${ }^{2}$.

Muestra 2: Las experiencias excepcionales de arquitectura están más allá del auto-control, trasportan la mente 


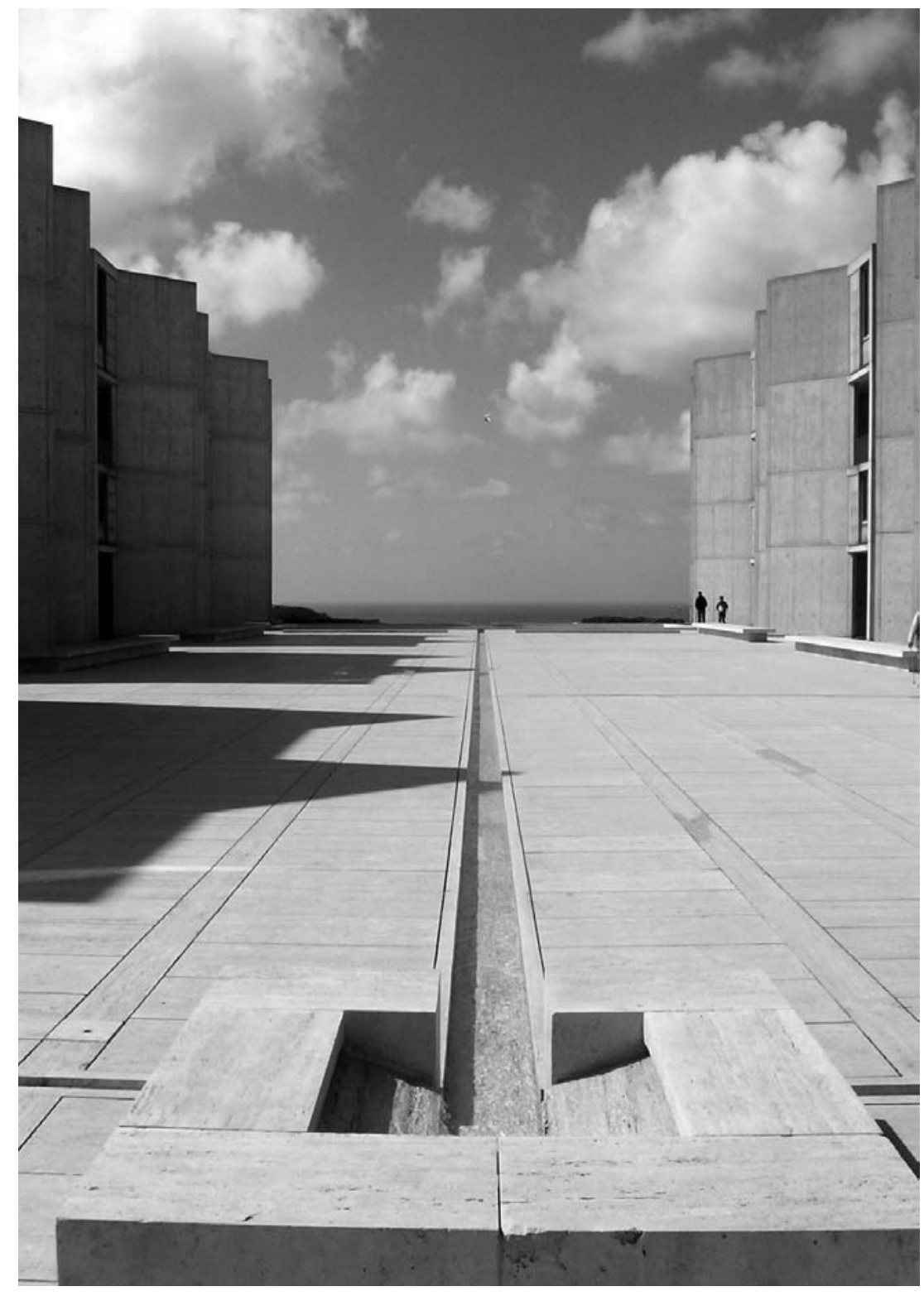

Figura 2. Arq. Louis Kahn: Instituto Salk, La Jolla, California, 1965. a una conciencia muy alta y pueden causar una transformación fundamental del ser. El investigador Lindsay Jones dice que una vez que se acepta «la tentadora invitación de la arquitectura, la persona puede ser profundamente transformada de maneras que van más allá del auto-control y poderes de reflexión auto-conciente». Tal experiencia «lo eleva a uno a niveles de conciencia más altos y a un conocimiento conciente espiritual de un modo en que la adquisición común de conocimientos no puede hacerlo». Tanto es así que estos eventos pueden causar «transformaciones que incluyen no sólo nuevas formas de pensar sino también de ser $^{3}$ ».

Muestra 3: La esencia de la arquitectura y el lugar puede ser experimentada pero no definida, puede ser notada pero finalmente es indescriptible. En su libro The Timeles Way of Building, el profesor Christopher Alexander se pregunta sobre qué es lo que causa las grandes experiencias de lugar y arquitectura. Reconociendo su incapacidad para describirlo o cuantificarlo, termina llamándolo «la cualidad sin nombre» y se maravilla ante su sutil pero poderosa naturaleza ${ }^{4}$.

Muestra 4: La verdadera apreciación de la arquitectura involucra una fenomenología excepcional que confiere una comprensión intuitiva fundamental y por lo tanto es fuente del más alto aprendizaje.

Recordando una historia sobre un estudiante de arquitectura envelezado por su experiencia en El Panteón, el editor de la revista Architectural Record de EEUU, Robert Ivy, escribe: «Esa historia nos Ilevó a muchos en la audiencia hacia nuestros propios momentos de reconocimiento (el afortunado, trascendental instante en que el universo se alineó y comprendimos el poder de la arquitectura). Para algunos, ese momento de reconocimiento arquitectónico pudo haber ocurrido ante el Instituto Salk, para otros ante Ronchamp. No todos han experimentado un ¡Aha!. Algunos maduran esa apreciación con el tiempo. La ruta es individual e inevitable... Frente a tal entendimiento intuitivo todo lo aprendido empalidece y las luces se debilitan» ${ }^{\mathbf{5}}$. 
Muestra 5: Las experiencias arquitectónicas excepcionales suspenden los marcos interpretativos habituales e inducen a una sensación de bienestar, armonía holística y presencia. Como profesional de la arquitectura y docente, a Heinrich Herman le interesa el diseño de obras que pueden enriquecer profundamente la experiencia de las personas. En tal búsqueda «se dio cuenta que la capacidad de un ambiente para inducir una dimensión poético-espiritual depende en hacer que la realidad del día a día del visitante/usuario se desplace temporariamente al fondo y así surja una apertura hacia la contemplación. Los procesos resultantes de la contemplación hacen que uno tome distancia de los típicos marcos de espacio, tiempo y ser, y pueden conducir a una sensación más fuerte de estar en el presente y a una mayor armonía de todo el ser» ${ }^{6}$.

Estas cinco muestras representativas evidencian con mucha fuerza que las estéticas arquitectónicas excepcionales son fenomenologías únicas que claramente se ubican por fuera de lo que es considerado experiencias normales de lugares y obras de arquitectura. Su estado de gran atención; las significativas irregularidades perceptuales; la disolución en la división objeto-sujeto; la íntima profundidad; la extática sensación de bienestar; el trascender de cultura y lenguaje y su potencial como transformador; desafían nuestras creencias, expectativas, ideas y conocimientos sobre la arquitectura, nosotros mismos, y aún más allá.

Hay dos eventos fenomenológicos independientes que son responsables por estas radicales consecuencias: uno es la experiencia estética extraordinaria en sí misma; el otro es la operación que permite que suceda, o sea una arrasadora reducción de todas las perturbaciones intelectuales, emocionales y sensitivas. Las dos secciones que se desarrollan a continuación se dedican a investigar dichos eventos.

\section{Experiencias arquitectónicas no-duales}

Si nos remitimos a la bibliografía y a nuestra propia vida, encontramos que los eventos estéticos excepcionales no son experimentados por demasiadas personas ni son fá- ciles que sucedan. Esto nos lleva a la pregunta: ¿por qué son fenomenologías tan poco usuales?

James Elkins en su libro Pictures and Tears (Cuadros y Lágrimas) ofrece una posible respuesta ${ }^{7}$. Este trabajo considera la sorprendente inhabilidad de la mayoría de académicos y críticos de arte para ser tocados experiencialmente por el arte, particularmente por la pintura. Esto es especialmente intrigante ya que ellos tienen una alta formación en arte y supuestamente son los que están mejor predispuestos a apreciarlo. Elkins usa el término «llorar» para medir empíricamente la pérdida de auto-control sobre la reacción de uno ante un evento estético. En otras palabras, el llanto demuestra un estado fenomenológico extremo de disfrute estético intenso. Elkins muestra que el fracaso de los profesionales del arte en alcanzar un rapto estético se debe a su arduamente ganada pericia. Por ejemplo, cuando los expertos en arte están frente a una pintura no pueden más que utilizar sus conocimientos, habilidades y destrezas críticas; como este abordaje es básicamente lógico-analítico depende de establecer una distancia objetiva entre el crítico y la pieza de arte. La separación intelectual que se produce crea un escudo cognitivo que impide el desarrollo de la necesaria íntima relación con la obra de arte para que se provoque la excitación estética. ¡Su misma forma de mirar es la que genera la brecha! Lamentablemente esta enfermedad está lejos de limitarse a los profesionales del arte sino que también afecta a la mayoría de arquitectos y diseñadores (y hasta a casi todas las personas exitosas en la altamente intelectualizada sociedad contemporánea como Elkins y otros lo sostienen) ${ }^{8}$. La cura fenomenológica a esta impotencia estética es simple pero, como veremos, no es fácil de implementar. Demanda un desplazamiento desde la experiencia dual a la no-dual. Poniéndolo en palabras del filósofo Ken Wilber, ${ }^{9}$ la estética extraordinaria requiere de un cambio fenomenológico fundamental, de un desprendimiento de tercera-persona a una intimidad de primera-persona. Lo que significa que mi (yo) experiencia ante un lugar (eso) debe cambiar entre yo y eso como dualidad a una unidad experiencial donde sujeto y objeto estén fusionados
Otras fuentes excelentes que no fueron seleccionadas entre las cinco finales son: Holl, S.: Archetypal Experiences of Architecture. $A+U$ : Questions of Perception. Edición especial, 1994, pp. 121-135. Kahn, L. (1979): Between Silence and Light. Shambala, Boulder. Silvestrin, C. (1999): Claudio Silvestrin. Birkhaüser, Basel. Zumthor, P. (2004):

Pensar La Arquitectura. Editorial G. Gili, Barcelona.

Franks, F. (1979): The Awakened Eye. Vintage Books, New York, p. 11

Jones, L. (2000): The Hermeneutics of Sacred Architecture.

Harvard University Press, Cambridge, pp. 97/102.

Alexander, C. (1979): The Timeless Way of Building. Oxford University Press, New York.

Ivy, R. (2006): «The Essence of Education» (Editorial). Architectural Record '07. p.17. 6 Hermann, H.: "On The Transcendent In Landscapes of Contemplation». En: Krinke, R. (ed.): Contemporary Landscape of Contemplation. Routledge, New York, pp. 36-37.

Elkins, J. (2001): Pictures \& Tears. Routledge, New York.

Albretch, J. (2002): «Against the Interpretation of Architecture». Journal of Architectural Education, 55:3, pp. 194-196.

Berman, M. (1984):

The Reenchantment of the World. Bantam Books, New York.

Harrison, E. (1985): Masks of the Universe. Macmillan Publishing Co. New York.

Sontag, S. (2007): Contra la interpretación y otros ensayos. Debolsillo, Barcelona.

9 Wilber, K. (1994): Psicología integral. Kairos, Barcelona. 
Figura 3. Aquí vemos una representación en tercera persona del momento en que San Francisco estaba muriendo. Comparar por favor con Figura 4. Figura 4. Versión en primer persona del evento representado en figura 3. Uno casi puede encarna los últimos momentos del santo. La diferencia entre esta y la vesión anterior ejemplifica la distinción fundamental entre perspectivas de primera y tercera persona. También nos enseña que las dos son necesarias para tener un interpretación más adecuada de lo sucedido.
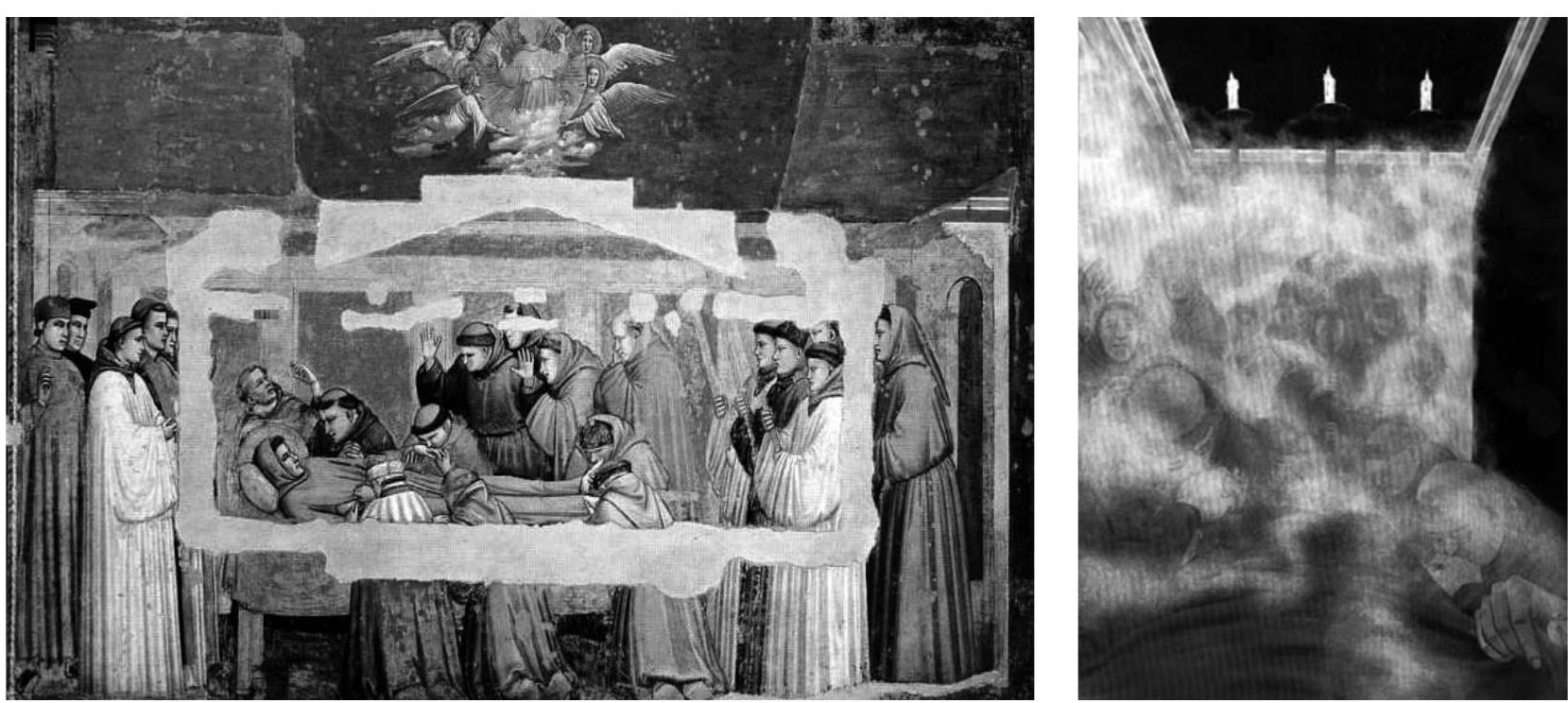

Figura 3. Giotto: La muerte de San Francisco, Capilla de Bardi en Santa Croce, Florencia, circa 1325. Figura 4. La muerte de San Francisco (basado en Giotto) por Kathleen Frugé-Brown. En: Glen Dunlap, L. (texto); Frugé-Brown, K. (pinturas) (1996): And I, Frances. Continuum, New York.

$(y o=e s o)$. Los métodos fenomenológicos tradicionales nos brindan la capacidad para movernos desde el limitante e instrumental punto de vista de la arquitectura como un hecho inerte al que se aborda desde la exterioridad (un eso), hacia una materialidad intencionada que interactúa activamente con nosotros en un significativo diálogo experiencial (un $t u$ ). Los beneficios otorgados por este cambio han sido bien documentados. Pero, a pesar de que dicho cambio fenomenológico de la tercera a la segunda-persona va en una buena dirección, no es suficiente para desplazarnos del dualismo. Es necesario un cambio final y radical hacia una identificación en primera-persona $(y o=t u=e s o$ ) para poder alcanzar una experiencia estética superior.

Las fenomenologías en primera-persona consiguen ser simultáneamente desinteresadas e íntimas. Esto explica por qué una experiencia estética conmovedora puede al mismo tiempo sobrepasar nuestra voluntad y ser tan íntima y profundamente introspectiva. Elkins nos da muchos ejemplos donde la gente se encuentra llorando de júbilo ante la belleza sin saber muy bien porqué o cómo llegaron a ese estado. Pero, ¿es ésto posible? Para responder, consideremos una experiencia excepcional (idealmente de arquitectura, pero si el lector no ha vivido ninguna de ellas, entonces tomemos cualquier otra mientras pueda ser califica como única).

A pesar de que está claro que uno mismo está presente durante las experiencias extremas (y por lo tanto conciente de lo que está sucediendo) también es evidente que no es mi yo habitual. Porque tan pronto como mi usual yo observa mi éxtasis estético, ese mismo sentimiento comienza a retroceder en la misma proporción en que incremento el automonitoreo. En cuanto comienzo a deslizarme de la fenomenología de primera-persona a la de segunda, o incluso a la de tercera, es que me doy cuenta y deseo salirme de esa disturbadora observación. Pero cuanto más trato de hacerlo, más rápidamente el inefable momento se diluye hasta que vuelvo a mi yo y 
al eso como entes separados, o sea a la fenomenología de tercera-persona. ¿Quién no ha vivido esta frustrante experiencia en algún momento de su vida? Se siente como perder la gracia. En los casos descriptos por Elkins, la verificación auto-conciente del llanto es el beso de la muerte ya que la emocionante experiencia estética desciende así de rápido de la fenomenología de primera a la de tercera-persona.

Se debe enfatizar que la conciencia no está nunca ausente durante el despertar estético, lo que está ausente es la conciencia de uno mismo. No existe un ego-observador que comente, juzgue y termine saboteando la gran experiencia, o diciéndolo de otro modo, las estéticas excepcionales son experiencias altamente concientes sin ego. Esto es lo que significa la fenomenología no-dual o de primera-persona: la falta de separación entre sujeto y objeto, la fusión de ellos en una sola entidad de espíritu. En este estado todo es subjetivo, u objetivo, o más precisamente solo la experiencia en desarrollo. Pero si esto es así, nos debemos preguntar entonces ¿quién o qué es lo que está concientemente presente y que no perturba el gran momento estético? Podemos decir que es un tipo de conciencia perceptual no inhibida por los marcos comunes de interpretación (incluyendo al yo mismo). Podríamos Ilamarlo ser-como-conciencia. La discusión hasta ahora indica la dificultad involucrada en alcanzar y sostener el espacio no-dual necesario para que se produzca una experiencia arquitectónica excepcional.

Queda explícito en este argumento, y absolutamente claro en las muestras compartidas anteriormente, que las estéticas extraordinarias de arquitectura consiguen desvanecer los filtros cognitivos así como las perturbaciones que usualmente ocupan nuestra mente. Tal purificación garantiza la transparencia requerida para ver la verdadera naturaleza de las cosas (el mundo) y el ser (la conciencia). Esto es un logro imponente desde cualquier punto de vista iporque implica una fenomenología que trasciende la cognición! Declarar que la estética excepcional comienza en la cognición y se mueve a modos de operación post-cognitivos no es poca cosa. Muchos de los esfuerzos del último medio siglo en la filosofía, en las ciencias sociales y en otras disciplinas se han dedicado a demostrar (supuestamente) la imposibilidad de tal trascendencia fenomenológica. $Y$ ahora vemos que ocurre. En la próxima sección vamos a profundizar este aspecto y proveer de más argumentos y evidencias que lo sostengan. Empezaremos por reconocer el paralelo entre el estado post-cognitivo inducido por las estéticas excepcionales y la reducción fenomenológica de Husserl.

\section{Las estéticas excepcionales \\ y la reducción fenomenológica de Husserl}

A principios del siglo XX Edmund Husserl propuso una filosofía de gran alcance basada en el método fenomenológico del «bracketing» ${ }^{10}$ (dejar entre paréntesis). Este procedimiento reductivo consiste en filtrar todos los sesgos no relacionados con la experiencia que está ocurriendo, como modo de acceder inmediatamente al contenido no contaminado de la conciencia: pura realidad.

Husserl construyó la reducción fenomenológica sobre dos grandes disernimientos filosóficos. Una vino de la distinción epistemológica de Kant entre fenómeno (la cosa como es experimentada) y noema (la cosa en sí misma). Su argumento de que el noema está para siempre más allá del acceso directo (sólo podemos experimentar la cosa, pero nunca ser la cosa) estableció que toda realidad es irremediablemente fenomenológica. El otro padre de la reducción fue el acto de la duda de Descartes. Llevando la duda a sus límites, Husserl se vio forzado a establecer un examen más que meticuloso de cada principio filosófico; al final se quedó con sólo el ser como conciencia fenomenológica. El desafío al que se enfrentó Husserl para hacer una revisión de la fenomenología del ser, fue encontrar un método que retirara el velo de prejuicio, sin con ello inhibir la operación conciente ${ }^{11}$. Volviendo a nuestro punto desarrollado anteriormente, él buscaba un procedimiento post-cognitivo; he aquí la descripción de la tarea de la reducción fenomenológica. Por lo tanto, la reducción fenomenológica es un acto de suspensión y no de transformación. No cambia la tesis o creencia hacia lo opuesto, ni la convierte en una presunción, una sugestión, una indecisión, ni una duda. La 

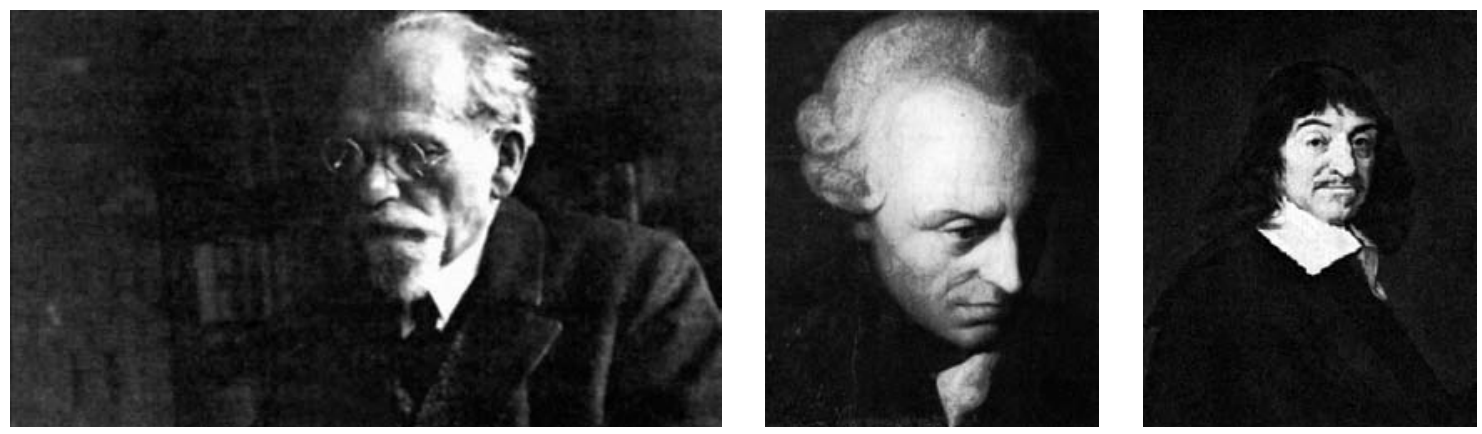

Figura 5. De izquierda a derecha: el filósofo Edmund Husserl (1859-1938); el filósofo Immanuel Kant (1724-1804); el filósofo René Descartes (1596-1650). Imágenes extraídas de Wikipedia (http://en.wikipedia.org) y http://www.joelsmith.net/phenomenology.htm

10 Husserl, E. (1931): Ideas: General Introduction to Pure Phenomenology. G.Allen \& Unwin Ltd., London. En castellano ha sido traducico como: Ideas relativas a fenomenología pura y filosofía fenomenológica. Fondo de Cultura Económica de España, Madrid, 1993. 11 Husserl frecuentemente hablaba de la Fenomenología como una "filosofía de principiantes" $y$ de la necesidad de reconsiderar completamente las fundaciones básicas de la filosofía, como un principiante que no sabe nada. Husserl, ibid.

12 Husserl, ibid., p. 108

13 Watts, A. (2003): El camino del Zen. Edhasa, Barcelona. Brahm, A. (2006): «Degrees of Seeing». Buddhadharma, 5:1, pp. 42-47.

14 Ver por ejemplo:

Hiss, T. (1990): The Experience

of Place. Knopf, New York.

Howett, C.: «If The Doors of Perception were Cleansed».

En: Seamon, D. (ed.) (1993): Dwelling, Seeing, and Designing. NY: sunny Press, Albany. Jacks, B. (2004): «Reimagining Walking. Four Practices». Journal of Architectural Education, 53:3, pp. 5-9. Krinke, R. (ed.) (2005): Contemporary Landscape of Contemplation. Routledge, NY. 15 Dewey, J. (2008): El arte como Experiencia. Ediciones Paidós, Barcelona. Heidegger, M. (1971): Poetry, Language, Thought. Harper \& Row Publishers, New York. reducción tampoco implica el abandono de la tesis ni un cambio de convicción. Solamente significa frenar su aplicación. Husserl dice: "La consideramos como si estuviera "fuera de acción"; la "desconectamos"; la "ponemos entre paréntesis". Permanece allí como lo que está dentro del paréntesis, como lo desconectado fuera del sistema de conexión. También podemos decir: la tesis es experiencia como vivida, pero "no hacemos uso de ella"»"12.

A pesar de que existe una gran diferencia en el rol que juega la intención en la reducción fenomenológica y en las estéticas excepcionales (la primera demanda de un acto inicial de intención voluntaria, mientras que la otra tiende a suceder espontáneamente, o sea, no-intencionalmente); hay sin embargo mucho en común en las características y resultados de ambas. Tal comparación se facilita si se consideran otros métodos reductivos intencionales, como por ejemplo la práctica de meditación del Budismo Mahayana. La meditación es un acto progresivo y deliberado de dejar ir lo sensorial y lo cognitivo para acceder a un estado de conciencia no condicionada. Este método reductivo lleva a un estado intenso de concentración conciente (samadhi) que silencia los condicionamientos y transporta al que medita a un estado mental no-dual con acceso a la realidad-como-es (tathata $)^{13}$. Basándose en la literatura y relatos personales de expertos en meditación, la reducción extrema operada a través de una profunda meditación tiene mucho en común con las estéticas extraordinarias y la reducción de Husserl. ${ }^{14}$

Lo común a estas tres (y otras) reducciones es la liberación del individuo de las prácticas cognitivas habituales. Al suspender creencias, conocimiento y percepción normal, buscan ver lo que realmente está allí y no lo que condicionadamente quiere ser visto. Su bracketing es tan radical que ni el ser-como-lo-conocemos escapa a él; todo lo que queda es un evento ocurriendo a un nivel de gran atención. En otras palabras, una transposición fundamental de una perspectiva dual a una no-dual genera una experiencia iluminada y no-común, o sea una intuición extremadamente vívida y transparente de los contenidos y la forma de la conciencia. Parafraseando a John Dewey, la verdadera estética es cuando la experiencia se transforma en el foco de la experiencia. 0 como diría Heidegger, la estética está cuando una experiencia aparece, esto es, cuando se hace conciente ${ }^{15}$.

Como lo adelantara anteriormente, se ha escrito mucho sobre la equivocación fundamental de la reducción fenomenológica. Filólogos, científicos sociales (estructuralistas y post-estructuralistas), psicólogos del comportamiento y cognitivos, estetas y otros; han construido excelentes argumentos demostrando, aparentemente, la imposibilidad de salirse de los marcos referenciales, ya sean lingüísticos, culturales, sociales, comportamenta- 
16 Por ejemplo, Eagleton, T. (1983): Literary Theory. An Introduction. University of Minnesota Press, Minneapolis.

${ }_{17}$ Csikszentmihalyi, M. (1998) Experiencia óptima: estudios psicológicos del flujo de la conciencia. Editorial Desclee de Brouwer, Vizcaya.

18 Austin, J. (1998): Zen And The Brain. MIT Press, Cambridge.

Suzuki, S.: Mente Zen, mente de principiante. Ediciones Troquel.

19 Edwards, B. (2000): Nuevo aprender a dibujar con el lado derecho del cerebro. Ediciones Urano, Barcelona. Ghiselin, B. (1952): The Creative Process. University of Californi Press, Berkeley.

Sloboda, J. (1988): Generative Processes in Music. Clarendon Press, Oxford. les, etc ${ }^{16}$. A pesar de ello, como lo he presentado, encontramos numerosos informes confiables sobre experiencias estéticas extraordinarias que son difíciles, si no imposibles, de comprender si se aplican los marcos habituales de significación. Otros casos bien documentados sobre extremas fenomenologías no-duales, tales como las de situaciones bajo experiencias pico ${ }^{17}$, meditación profunda ${ }^{18}$, y estados de alta creatividad ${ }^{19}$; sugieren persuasivamente que los argumentos que se oponen a la reducción fenomenológica tienen un alcance limitado.

Otra causa de resistencia y escepticismo contra la reducción es la real dificultad para llevarla a cabo: la puesta entre paréntesis del lenguaje, la cultura, y otras manifestaciones emocionales e intelectuales no es algo trivial. De hecho, su complejidad es seria pero no insalvable; aprender cómo se logra exitosamente una reducción requiere de substancial entrenamiento y práctica. Por ejemplo, los que se dedican a la meditación algunas veces se pasan décadas practicando las técnicas para alcanzarla; los atletas dedican largos años de entrenamientos extenuantes y luego usualmente se arriesgan para lograr una experiencia pico; también es grande el esfuerzo, tiempo y dedicación personal que sustentan los artistas y diseñadores para llegar a estados de alta creatividad. Lo raro de las experiencias estéticas excepcionales solamente agrega evidencia a la inherente dificultad en alcanzar extremos eventos no-duales. Pero el sólo hecho de que sí ocurren demuestra el poder y la realidad de tales fenomenologías de primera-persona. Puede muy bien ser que la reducción fenomenológica sea un arte difícil de dominar, y no algo estructuralmente imposible de alcanzar por los seres humanos.

\section{Conclusiones}

A pesar de que un gran logro de la fenomenología ha sido dar comprensión y legitimidad a la profunda relación entre ser y lugar, se ha quedado corta en hacer el gran salto al no-dualismo. Examinar experiencias estéticas excepcionales muestra que lo que usualmente aparece como relatos fenomenológicos (por ejemplo: construcciones intelectuales holísticas, interpretaciones hermenéuticas, relaciones arquetípicas, etc.) son todavía experiencias atrapadas a medio camino entre estados no-duales y percepciones dualistas de sentido común.

Así como no podemos hablar de un único paradigma para describir todos los fenómenos en Física (los modelos Cuánticos, Newtonianos y Relativistas trabajan perfectamente en diferentes escalas espacio-tiempo), un solo tipo de fenomenología no puede abarcar el inagotable campo del ser como conciencia. Sería mucho más realista y útil considerar diferentes fenomenologías para describir experiencias que suceden en situaciones substancialmente distintas. Podríamos concebir fenomenologías de primera, segunda y tercera-persona en disciplinada armonía, cada una refiriéndose a diferentes condiciones a través de una variedad de métodos reductivos. La fenomenología integral resultante nos permitiría llevar adelante un rango mucho más amplio de indagaciones de lo que es posible hoy. En el mismo sentido, nos permitiría conectar los discernimientos dispersos alcanzados por cada una separadamente y comenzar a construir un mapa del ser más amplio.

Lo que está claro, sin embargo, es que las experiencias estéticas excepcionales de arquitectura y lugar arriban a un estado trascendental donde la profunda sutileza del ser es liberadada del peso de los condicionamientos normales. No hay porqué disminuir el poder y la validez de las estéticas excepcionales de primera-persona.

Un abordaje mucho más productivo sería comprometerse en un serio y sistemático esfuerzo fenomenológico que nos lleve a (1) una mejor comprensión de las experiencias estéticas no-duales, incluyendo a otras experiencias de reducción, (2) el estudio del rol del hábitat construido como un ingreso potencial a miradas trascendentales y (3) el desarrollo de una disciplina completa y bien balanceada que coordine las fenomenologías de primera, segunda y tercera-persona. 
Figuras 6,7 y 8.

Notre Dame du Haut,

o Ronchamp, Francia.

Arq. Le Corbusier, 1955.

Tres versiones.

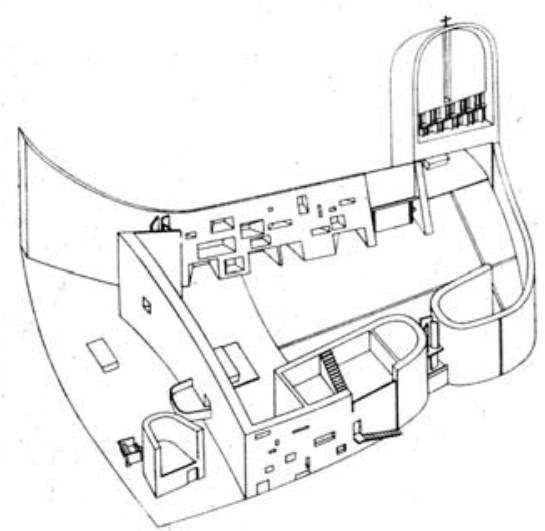

de compromiso experiencial del sujeto). Pero, en general, esta foto nos pone en una relación de apreciación que si bien es cercana, también está separada del edificio. La obra se nos aparece como un otro empáticamente transformado en un $t u$, o sea, en una relación o diálogo existencial conmigo. Finalmente, la figura 8 nos impele a sumergirnos completamente en una experiencia estética embriagante de luz, forma, y espacio. $\mathrm{Si}$ realmente aceptamos la invitación y abandonamos nuestro autoconcient yo en favor de la experiencia en sí, entonces ser arquitectónico y ser humano entran en una comunión o relación de primera persona. Es en esta situación desde donde se accede a la epifanía arquitectónica.

(aunque, seamos sinceros, esto es
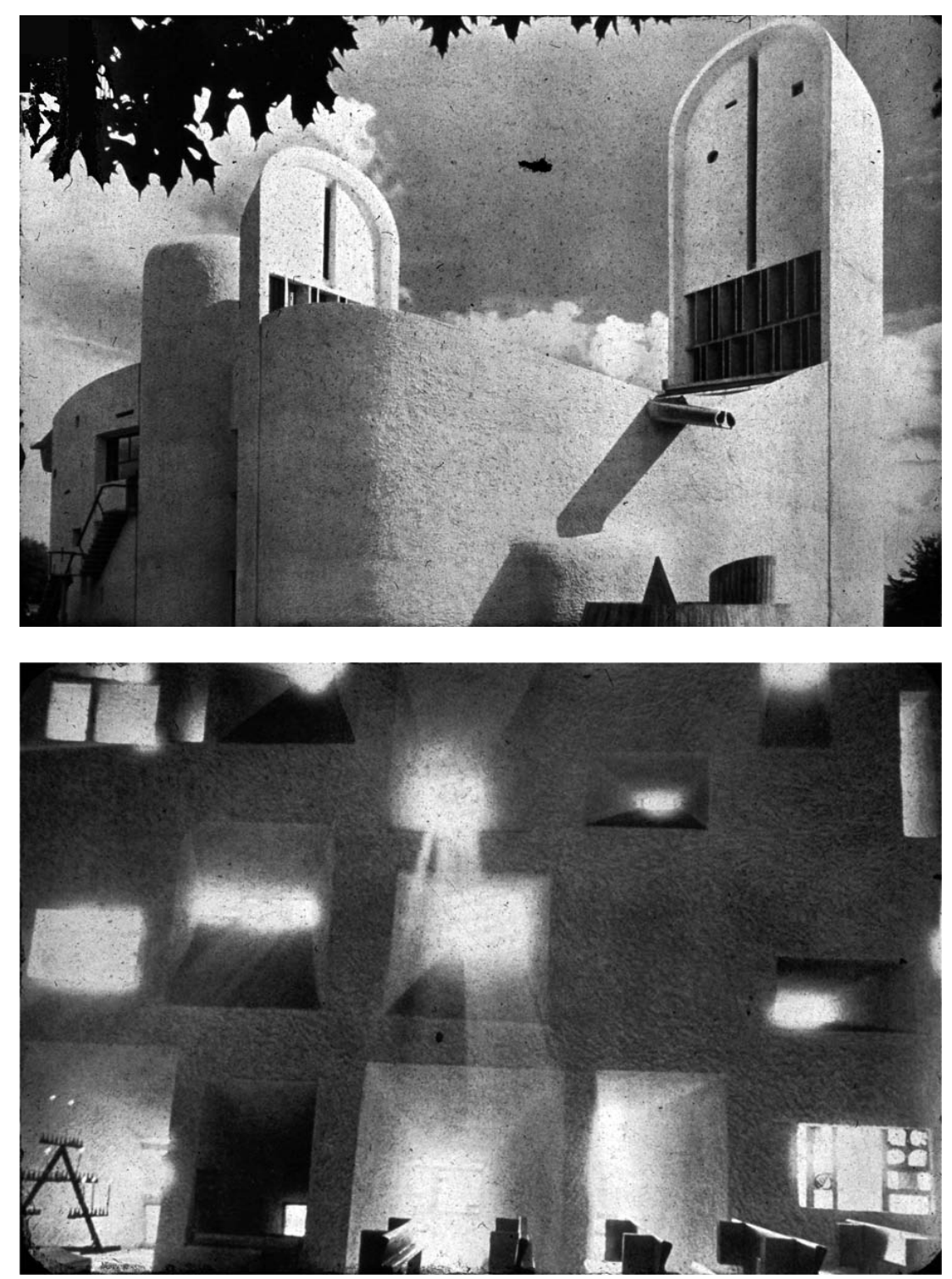